Open Access

\title{
Aging in cyberspace: Internet use and quality of life of older Chinese migrants
}

Jingjing Zhang

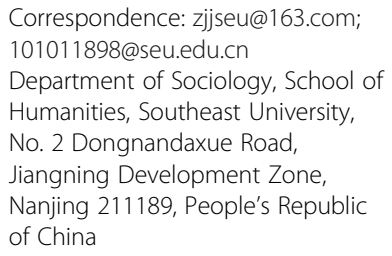

\begin{abstract}
In the transnational and digital era, the Internet plays an important role in the postmigration lives of many older migrants. This article explores how Internet use contributes to the quality of life of older Chinese migrants through the analysis of 19 qualitative interviews conducted in New Zealand. The results show that older migrants use the Internet to combat postmigration loneliness, to strengthen local and international social connectedness, and to cope with difficulties while settling in the host society. These findings suggest that older migrants use the Internet as a strategy not only to deal with issues related to aging but also to compensate for the losses and challenges caused by migration. In the migration context, independence fostered by the Internet is particularly highlighted as a key element in quality of life. By interrogating the roles the Internet plays in older Chinese migrants' day-to-day postmigration interactions, this article provides insights into their quality of life in a transnational context.
\end{abstract}

Keywords: Internet use, Quality of life, Transnational, Older Chinese migrant

\section{Introduction}

In the current digital era, the Internet plays an important role in the daily life of migrants. It helps facilitate their settlement and adjustment to a new society, strengthen connections with their homeland, and develop a transnational lifestyle (e.g., Bailey et al. 2007; Khvorostianov et al. 2012). However, little attention has been paid to older migrants' Internet use (Heikkinen and Lumme-Sandt 2013; Khvorostianov et al. 2012), probably because a much lower proportion of older people use the Internet compared to younger generations (Hilt and Lipschultz 2004). It is believed that older migrants are even less likely than native seniors to learn computer skills or access the Internet due to language barriers and lower socioeconomic status, which results in a higher risk of social exclusion (Mordini et al. 2009).

The existing literature suggests that older people can benefit from Internet use in a variety of aspects including heath, well-being, and social connectedness (Gardner et al. 2012; Kamal and Patil 2004; Mellor et al. 2008). The major uses of the Internet, including emailing, searching for information, online shopping, e-banking, and entertainment (Nie 2001), help older people maintain connections in their social relationships, enhance their physical and mental health, and have more leisure options (Gatto and Tak 2008; Kamal and Patil 2004; Pew Internet and American Life Project 2004). 
These findings lead to further questions: will older migrants benefit from the Internet in the same way? What are their perceptions regarding use of the Internet?

This article uses older Chinese migrants ${ }^{1}$ in New Zealand as a case study to illustrate the relationship between Internet use and older migrants' quality of life by looking at how and why they use the Internet in their day-to-day life, and how the Internet impacts their perceptions of quality of postmigration life. Based on the "thick description" generated from the interview data, this article highlights the particular circumstances faced by the participants, who are both migrants and older people. By interrogating the role of the Internet, this article provides a new perspective to understanding older migrants' quality of life in a transnational and digital context.

\section{Literature review}

In the current digital era, the Internet has reshaped many social interactions and daily activities. Given that a much lower proportion of older people use the Internet compared to younger generations, some scholars suggest that older people, especially the "oldest old," are more likely to experience the disadvantages of the "digital divide," which may result in new forms of isolation and marginalization (Gardner et al. 2012; Hilt and Lipschultz 2004). Such problems could consequently lead to the deterioration of physical health and psychological well-being, since many scholars have suggested that a good quality of life is positively associated with active social participation and supportive social networks (Bowling 2005b; Gallicchio et al. 2007; Wilkinson and Marmot 2003). In order to enhance their quality of life, in many countries, older people are encouraged to learn computer skills and use the Internet in their daily practices (see, e.g., Gardner et al. 2012; Richardson et al. 2005).

Many studies have focused on the positive health outcomes facilitated by the Internet use of older people. It is widely held that the Internet enables older people to receive more health-related information and medical services (Gardner et al. 2012; Hilt and Lipschultz 2004; Pew Internet and American Life Project 2004). For example, in Australia, the Internet has been suggested as a possible means of promoting preventive health behaviors to reduce the rising cost of healthcare in the aging population (Zajac et al. 2012). Elderly netizens also often visit health Web sites to check information on prescription drugs and healthcare. A descriptive study conducted in the USA demonstrates that using the Internet helps older people to gain new knowledge about their diseases, medical treatment options, and drug therapy (Gatto and Tak 2008).

Apart from accessing health-related information, it is also common to see that many older people surf the Internet to access information related to their personal interests, such as travel, vacation, and humor (Kamal and Patil 2004). The richness of online information and resources provides older people with various forms of entertainment after retirement (Mellor et al. 2008; Shiang et al. 2013). Many qualitative studies demonstrate that older people express happiness and satisfaction with the availability and ease of retrieval of online information (Gatto and Tak 2008; Hilt and Lipschultz 2004).

The Internet also provides older people with additional options to maintain social participation (Gardner et al. 2012; Mellor et al. 2008). Some scholars argue that as people grow old they are more likely to experience hearing and mobility issues and become isolated in their own homes. The lack of social activities and interactions results in feelings of boredom, loneliness, and unhappiness (Mellor et al. 2008; Victor et al. 2000). Although some scholars argue that using the Internet and social media 
results in less face-to-face communication (Odacı and Çelik 2013), other studies suggest that for the elderly who suffer from social isolation, the Internet actually provides them with new means of engaging with others (Mellor et al. 2008). They can use the Internet to search for and purchase products of different kinds and accomplish financial transactions through online banking (Nie 2001), which subsequently reduces the possibility of social exclusion (Land 1996).

Connections through social networks that include family and friends are crucial to the psychological well-being of older individuals (Chappell and Badger 1989; Palys and Little 1980; Victor et al. 2000). Older people use the two most common functions, email and online chat, to maintain communication with family and friends (Kamal and Patil 2004; Nie 2001). A study conducted in Japan shows that elderly Internet users who build up supportive and companionship relationships through exchanging emails usually feel well cared for and connected with others (Kanayama 2003).

The above literature demonstrates the various benefits that the Internet brings to older individuals; older people are thus generally encouraged to use the Internet to enhance their quality of life. Compared with their nonmigrant counterparts, older migrants face not only issues caused by aging, such as feelings of boredom, declining physical mobility, and shrinking social contacts (see, e.g., Mellor et al. 2008) but also challenges generated in the migration context. Physically separated from their families and established social networks in their home country, older migrants tend to face more difficulties in social participation and support (Bajekal et al. 2004; Tsang et al. 2004; Zhou 2012). Language and cultural barriers also mean that there is a higher risk of social isolation for older migrants in the host country (Ip et al. 2007; Treas and Mazumdar 2002). These difficulties and disadvantaged circumstances suggest that older migrants may have a greater need to learn computer skills and use the Internet. They may also have different interpretations of their postmigration Internet use. Therefore, further research needs to explore the Internet use of older migrants and how Internet use has impacted their quality of life.

\section{Method and data}

Data presented in this article were drawn from a larger qualitative study that aimed to understand the perceptions of social support and quality of life of older Chinese migrants living in New Zealand. Thus, the original research design did not single out Internet use as the influencing factor of quality of life. However, during the process of the research, the relevance of the Internet emerged from the interview data, suggesting its importance to the quality of life of the participants. This captured the immediate interest of the researcher, and more attention was hence given to Internet use during data collection and analysis.

\section{Qualitative methodology}

The entire project was guided by a qualitative methodology, using semistructured in-depth interviews and secondary data analysis as the main methods. The choice of qualitative methodology was mainly informed by the subjective approach to studying quality of life. According to the World Health Organization (1997), quality of life is an "individual's perception of their position in life in the context of the culture and value systems in which they live and in relation to their goals, expectations, standards and concerns. A broad ranging concept affected in a complex way by the person's physical 
health, psychological state, level of independence, social relationships, personal beliefs and their relationship to salient features of their environment" (World Health Organization 1997: 1).

Based on the widely accepted definition, many scholars argue that although people's quality of life is heavily affected by objective components of their living conditions and life circumstances, the evaluation of their overall quality of life only makes sense via people's own experience and perceptions (Bowling 2007; Campbell et al. 1976; Schuessler and Fisher 1985; Walker 2005). This is especially the case for older people because their quality of life in later life cannot be separated from the past and its social context. With regard to older Chinese migrants, the potential variability in social and cultural circumstances makes the evaluation of their overall quality of life more complex. Interviews were thus employed in this study to convey a strong sense of process by seeing older migrants' perceptions or experiences in terms of streams of interdependent events and elements (Bryman 2008).

\section{Data collection and analysis}

The data were collected during November 2011 and May 2012. In total, 35 participants who were originally from mainland China, aged 60 years and over, and had been living in New Zealand for over 3 years were interviewed in Auckland, New Zealand's largest city. Several approaches, including personal networks, advertisements, and snowballing, were employed to recruit participants.

An interview guide was used to facilitate and guide the interview process. Participants were asked to comment on various topics related to their migration process and postmigration lives, including their reasons for migration, settlement process, family relationships, personal networks, and social participation. They were also asked to list factors important to their quality of life and provide an overall evaluation of their life satisfaction pre- and postmigration. The length of the interviews ranged from one to two and a half hours. Although two language options-English or Mandarin Chinese-were provided, 34 of the 35 participants chose to be interviewed in Mandarin Chinese.

Using thematic analysis, the interview data were "segmented, categorized, summarized, and reconstructed in a way that captures the important concepts within the data set" (Given 2008, p. 867). Following both deductive and inductive approaches, all the interview transcripts were coded and analytical categories were identified as they emerged from the data. In order to capture "explicit and implicit meanings embedded in the Asian language, as well as culturally specific expressions and concepts" (Suh et al. 2009: 198), a postanalysis translation approach was employed. Only illustrative verbatim comments of the participants were translated into English during the reporting phase.

As a result, 19 participants (over half of the sample) talked spontaneously about Internet and computer use and its importance to their postmigration lives. The remaining 16 participants did not use the Internet. Given that the main purpose of this article is to explore the relationship between Internet use and quality of life of older Chinese migrants, the analysis mainly focuses on the interviews with the 19 Internet users. During the analysis, emphasis was given to their experiences of using the Internet, including why and how they used the Internet, aspects of their daily life influenced by the Internet, and their perceptions of Internet use. 


\section{Participant profile}

The 19 Internet users were all permanent residents or citizens of New Zealand, aged from 63 to 82 . Nine were males and ten were females. The length of time they had lived in New Zealand varied from 5 to 24 years. Sixteen of these Internet users had undertaken tertiary education (college/university and above), and the other three were high school graduates. In addition, the participants were living in different types of households. Six were living together with their adult children; the other 13 were living alone or with their partners (for details, see Table 1).

Although this article does not focus on comparing Internet users and nonusers, it is relevant to point out that there are clear differences between the two groups regarding their sociodemographic features. As shown in Table 2, the average age of Internet users was lower than the nonusers. Internet users also tended to have a much higher educational level than those who did not use the Internet. The results are in line with other statistics suggesting that younger and well-educated seniors adopt the Internet at higher rates than those who are older and with lower educational attainment (Pew Internet and American Life Project 2004). There is no noteworthy difference with regard to gender and living arrangements.

Patterns emerged from the interview data with regard to three aspects of advantages that the Internet brought to the participants' quality of life. The findings section of the article is structured around three themes-enriching daily life, strengthening social relationships, and enhancing independence. The findings and arguments mainly rely on

Table 1 Participants profile (19 internet users)

\begin{tabular}{lllllllll}
\hline No. & Pseudonym & Age & Sex & $\begin{array}{l}\text { Marital } \\
\text { status }\end{array}$ & $\begin{array}{l}\text { Educational } \\
\text { level }\end{array}$ & $\begin{array}{l}\text { Migration } \\
\text { category }^{\text {a }}\end{array}$ & $\begin{array}{l}\text { Year of migration } \\
\text { to NZ }\end{array}$ & $\begin{array}{l}\text { Working } \\
\text { status }\end{array}$ \\
\hline 1 & Mr. Lee & 75 & M & Married & University & FP & 2002 & Retired \\
2 & Mrs. Zhen & 68 & F & Widowed & College & FP & 1998 & Retired \\
3 & Mr. Hong & 76 & M & Married & University & FP & 1997 & Retired \\
4 & Mrs. Xiu & 75 & F & Widowed & University & FP & 1997 & Retired \\
5 & Mr. Tong & 63 & M & Remarried & University & FP & 2007 & Part-time \\
6 & Mrs. Qi & 64 & F & Married & Senior high & FP & 2007 & Retired \\
7 & Mr. Yu & 76 & M & Married & University & FP & 2002 & Retired \\
8 & Mrs. Yu & 73 & F & Married & College & FP & 2002 & Retired \\
9 & Mrs. Ai & 67 & F & Married & Senior high & FP & 2004 & Retired \\
10 & Mrs. Hui & 72 & F & Married & College & FP & 2003 & Retired \\
11 & Mr. Guo & 80 & M & Married & University & FP & 1998 & Retired \\
12 & Mrs. Guo & 82 & F & Married & University & FP & 1998 & Retired \\
13 & Mr. Tao & 75 & M & Divorced & University & FP & 1998 & Retired \\
14 & Mrs. Lin & 70 & F & Married & College & FP & 1998 & Retired \\
15 & Mrs. Yang & 78 & F & Widowed & University & FP & 2003 & Retired \\
16 & Mr. Zhou & 71 & M & Married & Senior high & FP & 1997 & Retired \\
17 & Mr. Hua & 66 & M & Married & PhD & SK & 1992 & Full-time \\
18 & Mr. Cheng & 74 & M & Married & PhD & SK & 1988 & Part-time \\
19 & Mrs. Cheng & 77 & F & Married & University & SK & 1990 & Retired \\
\hline
\end{tabular}

a"FP" indicates family-parent migrants sponsored by their adult children in applying for a New Zealand visa. "SK" indicatesskilled migrants who independently received a New Zealand visa for work reasons 
Table 2 Profiles of Internet users and nonusers

\begin{tabular}{llcll}
\hline Internet use & Number of participants & Average age & Tertiary education & Living arrangements \\
\hline Users & $19(9 \mathrm{M}, 10 \mathrm{~F})$ & 72.7 & 16 out of & 6 with adult children; \\
& & $1984.2 \%$ & $\begin{array}{l}13 \text { living alone or with } \\
\text { partner }\end{array}$ \\
Nonusers & $16(7 \mathrm{M}, 9 \mathrm{~F})$ & 74.6 & $\begin{array}{l}9 \text { out of } \\
1656.3 \%\end{array}$ & $\begin{array}{l}5 \text { with adult children; } \\
11 \text { living alone or with } \\
\text { partner }\end{array}$ \\
& & &
\end{tabular}

verbatim quotes of the 19 participants who used the Internet in their daily lives. Although the sample was not random or representative, the findings provide considerable insight into the Internet use and quality of life of older Chinese migrants.

\section{Findings}

\section{An enriched postmigration life with the Internet}

Nearly two thirds of the older Internet users in this study learned to use the Internet after their migration to New Zealand as a means of combating boredom and isolation in their postmigration lives. As recent arrivals reuniting with their adult children, these older Chinese migrants tended to center their lives around their family, providing domestic support and childcare to their grandchildren, and hence participated much less in the wider society (Zhang 2014). Furthermore, their social networks were usually small and confined within local Chinese communities due to their low level of English language proficiency and limited knowledge about the host society. Feelings of loneliness and isolation were common for these older migrants, especially at the early stage of their settlement in the host country.

To ease such feelings, they resorted to various forms of activity, including surfing the Internet, to fill up their "empty" lives. One participant, Mrs. Zhen (68, FP), ${ }^{2}$ stated "Having just arrived here with nothing to do, I stayed at home, feeling bored. So I started to learn to use the computer. I asked my son to teach me how to get online, and how to send emails." Another participant who had a similar experience, Mrs. Xiu (75, FP), reported "I started to learn computer skills when my husband passed away. I was alone; I wanted my life to be richer and more colourful, so I decided to learn to use the computer by myself." As these quotes show, the loneliness experienced by the two participants was likely the outcome of both migration and widowhood. Their limited social networks and lack of a companion with whom to engage in social activities increased their risk of social isolation in the host country. Arguably, Internet use became an effective means to combat loneliness in the participants' postmigration life.

Acquiring computer skills was not an easy task for them. Older people usually face more challenges when learning Internet skills, both practically and emotionally (Gardner et al. 2012; Kanayama 2003). For example, seniors reported more difficulties in understanding computer-related vocabulary than young people, and they felt a lack of confidence in mastering the complicated technology because of their perceived declining learning efficiency (Gardner et al. 2012; Kiel 2005; Richardson et al. 2005). However, due to these difficulties and challenges, the participants found it particularly fulfilling when they successfully acquired proper computer and Internet skills. For example, during the interview, Mrs. Yu (73, FP) proudly stated “I didn't know how to use the Internet 
at all, but now I know it. I feel very happy because I've learned new knowledge. ... I can do this just like those young people." Another participant, Mr. Lee (75, FP), expressed his opinion that "for people my age, we don't need to learn the computer as deeply as young people do. We just need to know some basic skills. That's good enough."

Establishing reasonable learning goals and mastering basic computer and Internet skills contributed to the older migrants' self-confidence and self-esteem. They tended to feel that they were better able to achieve an enriched daily life in the host country by exploiting the advantages brought about by the Internet. This echoes previous findings that suggest that accomplishing the challenge of learning computer skills gives older people a sense of fulfillment and confidence (Gardner et al. 2012; Gatto and Tak 2008). They also feel more mentally stimulated and connected to the modern world (Richardson et al. 2005).

The Internet offered older Chinese migrants an alternative means of pleasure, including access to news and information, videos, and television dramas, and more entertainment options. Although many still relied on "traditional" forms of Chinese-language media (i.e., newspapers, radio, television) for recreation, they had started to view the Internet as complementary to, or even better than, the traditional media. As a personalized form of media, the Internet empowers users to choose any form of information or entertainment at any time according to their personal interests and preferences. With the Internet, the participants said they no longer needed to worry about how to spend their free time when no attractive television/radio programs were available or nothing of interest in newspapers, as evidenced in Mrs. Lin's (70, FP) comment: "We used to read newspapers all the time; now we can find everything on the Internet. It's even better. I don't want to waste my time watching low-quality TV shows. I used to watch whatever was shown on the TV, but now I can choose what I want to watch on the Internet."

In addition, the Internet enables older Chinese migrants to access more Chinarelated information through visiting China-based Web sites. Since leisure and information are the two functions commonly embraced by elderly netizens in general, it does not seem groundbreaking to have similar findings in the present study. However, in the migration context, the Internet further opens a window for migrants to access information related to their home country and culture, alleviating the sense of being cut off from their homeland.

Similar to many other settler societies such as the USA, Australia, and Canada, the fast-developing Chinese-language media in New Zealand have provided Chinese migrants with easily accessible information and resources about the host society as well as local Chinese communities (Ip 2006), but these ethnic media hardly fulfill the migrants' need for authentic and rich information about their home country (Yin 2015). However, by using the Internet, older migrants could easily access information about China and therefore felt emotionally bonded to their homeland. They also found it easier to develop topics of conversation when they contacted relatives and friends who were still living in China.

It is arguable that the Internet has become a strong competitor to traditional media forms, and changes people's media habits (Findahl 2008). However, this study suggests that older migrants are more likely to view the Internet as a complement, rather than a replacement, to traditional media. This is probably because their media habits were established long before the emergence of digital technologies. Hence, the combination of using the Internet and traditional media helped them to achieve a more colorful life. 
For example, Mrs. Xiu (75, FP) described her typical day as follows: "Every morning I listen to the Chinese-language radio once I wake up. There is one hour of news and an English-language learning program. ... I use the computer and the Internet in the afternoon to read news and contact friends. If I still have spare time, I search for [Chinese] TV dramas on the Internet. ... My life is definitely enriched since having my computer." Similarly, eight other participants also explained in detail how they used the various forms of media to pass their leisure time, feeling that they were able to easily achieve a fulfilled daily life. The sense of enrichment contributed significantly to their postmigration quality of life.

\section{Strengthened transnational connections via the Internet}

The communication function of the Internet played another essential role in the participants' daily lives. To some extent, their enthusiasm to learn and use the computer and Internet was largely sparked by family members (usually children and grandchildren) and/or friends who were already Internet users. This further explains why most Internet users in this study were eager to learn to use the Internet after their migration. Apart from combating loneliness, they are also keen on exploiting whatever means possible to enhance their communication with family and friends in another country. The participants in this study reported a high frequency of using instant messaging platforms such as Skype or $\mathrm{QQ}^{3}$ to connect with family members living in other countries, and using email to contact friends in both China and New Zealand.

Among the 19 Internet users in this study, 12 had family members (children, grandchildren, or parents) living overseas, including in China, Australia, the USA, or Germany. The Internet enabled those older migrants to make low-cost but highquality contact with family members. One participant, Mr. Guo (80, FP), described how he used the Internet to stay in touch with his grandsons: "I have three grandsons, one is in China and the other two are in Australia. We see each other on the computer very often. They talk with me in a very intimate way. That comforts me." Another participant, Mrs. Hui (72, FP), said "When my elder son went to the United States [in the 1990s], I missed him very much. Many years later, we got computers. Every time we do a video chat I feel he is with me. Now we have video chats every two or three days."

Face-to-face chat significantly reduces the perceived physical distance among family members, creating a sense of "virtual intimacy" (Wilding 2006: 125). It makes older migrants feel that they are emotionally cared for by their children and grandchildren although they are not physically present. Different from family-parent migrants who moved to New Zealand to reunite with their children and grandchildren, three participants in this study were skilled migrants who moved to New Zealand at a younger age for better job opportunities. They thus tended to feel guilty for not providing enough care for their elderly parents. However, using the Internet facilitated the emotional care between generations. As Mr. Hua (66, SK) said, "I call my mum every week. Sometimes we use Skype so that we can actually see each other. My mum can't use it very well; if my sisters are there we use Skype, otherwise we just use phone calls."

Emailing was another communication tool used prevalently by the participants, mainly to contact peers in the home and host countries. Different from instant messaging, which is a synchronous communication tool requiring participants to be online at the same time, emailing overcomes differences in time zones. One participant, Mr. Hong (76, FP), 
believed emailing had changed his retirement life: "The first thing I do after getting up in the morning is check emails on my iPad. Because of the time difference, emails from my Chinese friends usually arrive at midnight. I read their emails in the morning, and then reply to them so my friends can read my emails when they get up." For Mr. Hong, reading emails from friends in China in the early morning was obviously enjoyable. Email allows messages to be sent at any time, with the recipient able to respond at his or her own convenience. The sense of transcending time and space contributes to a perception of intimate connectedness (Wilding 2006).

More importantly, these older Chinese migrants not only used email as more than merely a tool for contact but also to share life stories and personal interests and even for group chatting. Mrs. Xiu (75, FP) explained "We use email not for saying hello to friends. We mainly use it to communicate some ideas relevant to us older people, such as our perceptions of aging, our knowledge and information about health care." Similarly, some participants talked about how they used email to share their personal hobbies with friends, such as photography and traveling. They also exchanged viewpoints about international news and social issues occurring in New Zealand and China.

It is interesting to note that many Internet users in this study preferred to organize their "email friends" into groups according to residence (i.e., China or New Zealand) and personal hobbies. Given that their online communication was developed based on their existing relationships, this grouping method helped them develop different ways to maintain connections with both old friends in China and new social contacts in New Zealand. For example, Mr. Hong (76, FP) said "When I was in China I lived in many cities for study and work, so I have many friends living in various places. After coming to New Zealand, I have made new friends here. ... I organize them into different groups according to their residential places [China or New Zealand]. That saves me a lot of time when I send group emails to share interesting information with them."

Sending group emails changes the traditional one-to-one pattern of social contact and forms "electronic gatherings" among older people (Kamal and Patil 2004, 90). It provides a different trajectory in socializing regardless of physical distance. Internet-based gatherings allow participants to simultaneously discuss a wide variety of topics with other members of the same email group even when they live in different countries. Hence, the role played by the Internet is not just encouraging social communication but also reinforcing social connectedness by creating a virtual gathering space in the transnational context. As a result, migration in later life does not necessarily mean the termination of long-established social networks in the home country.

The participants in this study also reported a great sense of fulfillment through exchanging emails with friends. One possible explanation was that email offered a platform to share a variety of materials, both visible and audible, with friends. For older people in general, being able to provide valuable information can result in a sense of meaningfulness and fulfillment (Bowling 2005a). However, the sense of fulfillment for older migrants in this study was further magnified through a "cognitive comparison" mechanism (Veenhoven 2008: 46). Many of the participants believed that they were better able to access richer sources of information than their friends in China due to the lack of censorship in New Zealand. This perceived advantage of living abroad can also engender great satisfaction with their online communication. As Mr. Zhou (71, FP) said, "I send them [friends] information they cannot access in China. Things from YouTube, which they don't have access to [due to 
censorship]. ... This makes all of us happy. ... I can see a lot of interesting information and [China-related] news that they would never know, and I can share these through email to my friends who might be interested." Apart from exclusive information that they can access, the migration experience itself also provided topics of discussion that the older migrants could share with their peers in China. Many of the participants felt they had richer life experiences than their Chinese friends who had never migrated or traveled abroad. Therefore, they were more willing to initiate contact with their friends in China, such as sending New Zealand pictures or other traveling photos. This produced a sense of pride during their online communications. All these positive emotions undeniably contributed to good morale and self-confidence.

\section{A newly built independence}

Previous studies on elderly Internet users seldom discuss the importance of the independence fostered by the Internet, even though most older people appreciate being able to access a massive amount of information (e.g., Henke 1999). However, for the older Chinese migrants in this study, independence was an outstanding theme frequently mentioned in their interviews. They believed that the Internet empowered them to foster a new sense of independence from their migration families, enabled them to deal with English language difficulties, and provided abundant information to cope with day-to-day living in the host society.

Data from this research show that the Internet helps to overcome difficulties caused by the English language barrier. Given that most older Chinese migrants who moved to New Zealand for family reunification had limited English language proficiency, their lives in New Zealand tended to be very dependent on their adult children. However, by using the Internet, they felt more capable of coping with language issues by themselves. In general, they used search engines and online dictionaries to look up the meanings of English words so that they could understand English letters that they received. They also used free online translation services to translate Chinese words into English when they needed to fill in official forms or documents. These tangible functions decreased their demand for English language support from their adult children or others. As Mrs. Lin (70, FP) expressed,

I felt it was necessary to learn how to use a computer. If I didn't learn, there would have been a lot of things I would never know and understand. ... Here [in New Zealand], you can't rely on your children for everything; you must have your autonomy. I'm getting old, and there are always things I want to do but unable to deal with, especially the difficulties of the English language. But I always try my best to find out solutions on the computer before asking for help.

Although the Internet did not necessarily improve the older migrants' English language skills, especially their spoken English, it provided an immediate tool to effectively cope with minor difficulties. It could also help in avoiding embarrassing moments experienced by many older migrants when they faced difficulty communicating with native language speakers. They thus developed a sense of managing and controlling their own lives without burdening their adult children. 
The importance of the Internet to the independence of older people was further highlighted by the trend that an increasing number of older Chinese migrants live separately from their adult children in New Zealand. This was either because their children had migrated to a third country (usually Australia) or because they wanted to pursue freedom and intimacy-at-a-distance (Zhang 2014). By accessing the abundant Chinese-language information on the Internet, the older migrants were able to obtain a better understanding of the host society and cope in their daily life. Mr. Yu (76, FP) had been living in New Zealand with his wife for over 10 years; during the interview, he commented "The Internet is my good friend. It's a treasure box of knowledge. Every time I come across a question, no matter what it's about, I can always find answers on the Internet."

Previous literature has identified that using search engines to seek useful information is very popular among older Internet users (Gatto and Tak 2008). Older Chinese migrants in particular pursued this function because they had a higher propensity of encountering difficulties in their daily lives due to language barriers. It was common among the participants to frequently browse ethnic Chinese Web sites to acquire New Zealand-related information, such as seeking rental accommodations or acquiring information about public transportation. They also accessed online services and facilities, including using public library services and obtaining information about community activities. However, very few of them used online banking to deal with transactions or to transfer money between their Chinese and New Zealand bank accounts. This was probably because their lack of understanding of the sophisticated technology made it difficult for them to trust e-banking (Benamati and Serva 2007). Moreover, their poor English language proficiency could further hinder their usage of New Zealand's online banking system.

In general, the Internet empowered the participants to maintain an independent life by providing them with a variety of information in every aspect of their daily lives. Some viewed the computer and Internet skills as "basic skills" for living in New Zealand. They believed that older migrants who could not use the computer and Internet were more likely to be at a disadvantage when settling in the host society. In contrast, those who had acquired the skills were better able to live an independent life in the new environment. The strong sense of independence and feeling of power over their own lives helped to enhance their self-esteem and well-being (Bowling 2005a).

\section{Discussion and conclusions}

Older migrants form a special cohort that copes with issues of natural aging as well as life transitions due to migration. While the digital divide largely marginalizes older individuals in the current Internet era, it seems that some older people have already embraced the new media technology to facilitate their daily activities. Although some aspects of Internet use by older Chinese migrants in this study are similar to the results found among the older population in general, the Internet seems to play a more important role for the older migrants. Not only does it aid in coping with mundane activities but it also has become a potent factor influencing their quality of life in three aspects: enriching daily life, maintaining and strengthening social relationships, and fostering a sense of independence.

The Internet enhances the quality of life of older Chinese migrants by enriching their postmigration daily life. This is especially important for those who experience English 
language barriers. A tremendous amount of Chinese-language media content is readily available through the Internet. Admittedly, many of these elderly migrants still use traditional media as their major source of entertainment; yet, the Internet as a complementary media form has broadened the media landscape for these older migrants. The wide variety of information on the Internet offers older people entertainment based on their personal choice. The tailor-made media content helps combat loneliness and isolation caused by language and cultural barriers.

The Internet also enables older Chinese migrants to maintain and strengthen their social relationships in both the home and host countries, contributing to their transnational lifestyles (Heikkinen and Lumme-Sandt 2013). Transcending geographic boundaries and time zones, the Internet as a transnational media provides continuous connections between the host and home countries. Older migrants can now participate in social activities through group emails with their peers and friends. Moreover, video chat over instant messaging platforms allows these older people to have enhanced connections with their family in other countries. Whereas low-cost calls were considered a kind of "social glue" connecting small-scale social formations across the globe (Vertovec 2004), the Internet has been able to push the boundary of transnational social formations and create a sense of "electronic gathering" (Kamal and Patil 2004: 90) among peers and "virtual intimacy" (Wilding 2006: 125) among family members. Maintaining connections with family members and close friends is especially important for older migrants when their social networks are shrinking due to a long absence from their homeland, as well as the death of old friends and siblings. Through Internet-enabled connections, older migrants perceive that they acquire more social support, both emotional and practical, that contributes to their well-being.

Most importantly, empowered by the Internet, older Chinese migrants develop a stronger sense of independence. They use the practical information on the Internet to cope with day-to-day difficulties. Knowledge about the host society makes them more confident about adjusting their lives to the new country. In this sense, the Internet helps older migrants to "navigate unknown and foreign territories" (Zhou and Cai 2002: 435). Most importantly, the task is done without the help of family and friends, imbuing the older migrants with a sense of fulfillment and self-esteem. It is necessary to mention that the autonomy and independence pursued by older Chinese migrants also demonstrates that their perceptions of quality of life evolved when the cultural, social, and economic environments changed as a result of their migration (Zhang 2014). Instead of emphasizing the importance of children's filial care to their quality of life, older Chinese migrants have adopted the concepts of positive and successful aging, believing in the importance of maintaining independence and having control over their own lives.

Similar to most other qualitative research, the present study has certain limitations that must be considered. The findings are mainly generated from interviews with 19 participants, representing a certain migration group in certain social contexts. Although their shared cultural background and similar lived experiences contribute to the internal validity of this study, the findings and arguments generated from their interview data cannot be generalized to the larger population or migrants with other cultural backgrounds. Even so, it is believed that the constraints and difficulties caused by the intersectionality of aging and being a minority migrant are shared with many older migrants, no matter what their 
cultural background is. Therefore, this study provides more insight into the digital life of older migrants in the transnational context.

Admittedly, the digital world is still dominated by younger generations and many seniors are yet to embrace the Internet as part of their lifestyle. Nonetheless, it is evident that the older Chinese migrants in this study have benefited from the Internet. For them, the Internet has become simultaneously a platform for enhanced social connections, a strategy to facilitate settlement and adjustment, and a source for a sense of fulfillment and independence. Internet use is thus increasingly important and relevant to a comprehensive understanding of the quality of life of older migrant populations. With the ever-growing number of elderly netizens, further research needs to be directed to the interaction between their quality of life and their participation in the digital world.

\section{Endnotes}

${ }^{1}$ In OECD countries, the term "older people" commonly refers to those aged 65 and over. However, in mainland China, the current official retirement age is 60 for men and 50 or 55 for women, depending on their occupation. Given that most older Chinese migrants move to New Zealand after their retirement in China, for this study, participants were recruited among Chinese migrants aged 60 and over.

${ }^{2}$ In this article, pseudonyms are used for participants followed by a code showing their age at the time of interview and their migration category. "FP" refers to family-parent migrants sponsored by their adult children when applying for a New Zealand visa. "SK" refers to skilled migrants who received a New Zealand visa independently for work reasons.

${ }^{3} \mathrm{QQ}$ is an instant messaging software commonly used in China. QQ offers a variety of services, including video chat, social network games, music, shopping, and microblogging.

Acknowledgements

Financial support for this research was provided by the University of Auckland, the China Scholarship Council (2010-2014), and the National Social Science Foundation of China (No. 15CSH077). Appreciation is extended to my participants, who generously shared their stories with me. Gratitude is expressed to Maureen Baker, Louise Humpage, and Hang Yin for their comments and suggestions on an earlier draft of this manuscript.

Competing interests

The author declares no competing interests.

Received: 11 April 2016 Accepted: 27 September 2016

Published online: 07 October 2016

References

Bailey, O.G., M. Georgiou, and R. Harindranth. 2007. Transnational Lives and the Media: Re-imagining Diasporas. New York: Palgrave Macmillan.

Bajekal, M., D. Blane, I. Grewal, S. Karlsen, and J. Nazroo. 2004. Ethnic Differences in Influences on Quality of Life at Older Ages. Ageing and Society 24: 709-28.

Benamati, J.S., and M.A. Serva. 2007. Trust and Distrust in Online Banking: Their Role in Developing Countries. Information Technology for Development 13(2): 161-75.

Bowling, A. 2005a. Ageing Well: Quality of Life in Old Age. Maidenhead: Open University Press.

Bowling, A. 2005b. Measuring Health: A Review of Quality of Life Measurement Scales, 3rd ed. Maidenhead: Open University Press.

Bowling, A. 2007. Quality of Life in Older Age: What Older People Say. In Quality of Life in Old Age International and Multi-disciplinary Perspectives, ed. H. Mollenkopf and A. Walker, 15-30. Dordrecht: Springer.

Bryman, A. 2008. Social Research Methods, 3rd ed. New York: Oxford University Press.

Campbell, A., P.E. Converse, and W.L. Rodgers. 1976. The Quality of American Life: Perceptions, Evaluations, and Satisfactions. New York: Russell Sage Foundation.

Chappell, N.L., and M. Badger. 1989. Social Isolation and Well-being. Journal of Gerontology: Social Sciences 44(5): S169-76.

Findahl, O. 2008. The Role of Internet in a Changing Mediascape: Competitor or Complement?". Observatorio Journal 2 : 209-22.

Gallicchio, L., S.C. Hoffman, and K.J. Helzlsouer. 2007. The Relationship between Gender, Social Support, and Health-related Quality of Life in a Community-based Study in Washington County, Maryland. Quality of Life Research 16: 777-86. 
Gardner, P.J., T. Kamber, and J. Netherland. 2012. Getting Turned on': Using ICT Training to Promote Active Ageing in New York City. The Journal of Community Informatics 8(1). http://www.ci-journal.net/index.php/ciej/article/view/809.

Gatto, S.L., and S.H. Tak. 2008. Computer, Internet, and E-mail Use among Older Adults: Benefits and Barriers. Educational Gerontology 34: 800-11.

Given, L.M. 2008. The SAGE Encyclopedia of Qualitative Research Methods. Los Angeles: SAGE Publications.

Heikkinen, S.J., and K. Lumme-Sandt. 2013. Transnational Connections of Later-life Migrants. Journal of Aging Studies 27(2): 198-206.

Henke, M. 1999. Promoting Independence in Older Persons through the Internet. Cyber Psychology and Behavior 2(6): $521-27$.

Hilt, M.L., and J.H. Lipschultz. 2004. Elderly Americans and the Internet: E-mail, TV news, information and entertainment websites. Educational Gerontology 30(1): 57-72.

Ip, D., C. Lui, and W. Chui. 2007. Veiled Entrapment: A Study of Social Isolation of Older Chinese Migrants in Brisbane Queensland. Ageing and Society 27: 719-38.

Ip, M. 2006. Chinese Media in New Zealand: Transnational Outpost of Unchecked Floodtide?". In Media and the Chinese Diaspora: Community, Communications and Commerce, ed. W. Sun, 178-200. London: Routledge.

Kamal, M., and G.D. Patil. 2004. Computer and Internet Uses among Elderly Population: Adding Activity and Quality to Life. Journal of Business and Economics Research 2(10): 87-90.

Kanayama, T. 2003. Ethnographic Research on the Experience of Japanese Elderly People Online. New Media and Society 5(2): 267-88.

Khvorostianov, N., N. Elias, and G. Nimrod. 2012. 'Without It I Am Nothing': The Internet in the Lives of Older Immigrants. New Media and Society 14(4): 583-99.

Kiel, J.M. 2005. The Digital Divide: Internet and E-mail Use by the Elderly. Informatics for Health and Social Care 30(1): 19-23.

Land, K.C. 1996. Social Indicators and the Quality-of-life: Where Do We Stand in the Mid-1990s. SINET 45: 5-8.

Mellor, D., L. Firth, and K. Moore. 2008. Can the Internet Improve the Well-being of the Elderly?". Ageing International 32: 25-42.

Mordini, E., D. Wright, P. De Hert, E. Mantovani, K.R. Wadhwa, J. Thestrup, and G. Van Steendam. 2009. Ethics, e-Inclusion and Ageing. Studies in Ethics, Law, and Technology 3(1): Article 5.

Nie, N.H. 2001. Sociability, Interpersonal Relations, and the Internet: Reconciling Conflicting Findings. American Behavioral Scientist 45(3): 420-35.

Odacl, H., and Ç.B. Çelik. 2013. Who are Problematic Internet Users? An Investigation of the Correlations between Problematic Internet Use and Shyness, Loneliness, Narcissism, Aggression and Self-perception. Computers in Human Behavior 29(6): 2382-87.

Palys, T.S., and B.R. Little. 1980. Social Indicators and the Quality of Life. Canadian Psychology 21(2): 67.

Pew Internet and American Life Project. 2004. Older Americans and the Internet. from Pew Internet and American Life Project. http://www.pewinternet.org/2004/03/28/older-americans-and-the-Internet/.

Richardson, M., C.K. Weaver, J. Zorn, and E. Theodore. 2005. 'Getting on': Older New Zealanders' Perceptions of Computing. New Media and Society 7(2): 219-45. doi:10.1177/1461444805050763.

Schuessler, K.F., and G.A. Fisher. 1985. Quality of Life Research and Sociology. Annual Review of Sociology 11(1): 129-49.

Shiang, J., C. Lee, C. Chen, and T. Huang. 2013. Are Elderly Netizens Unique? A Comparison of Four Different Populations. In Aging Society and ICT: Global Silver Innovation, vol. 5, ed. T. Obi, J.P. Auffret, and N. Iwasaki, 193-202. Amsterdam: IOS Press.

Suh, E.E., S. Kagan, and N. Strumpf. 2009. Cultural Competence in Qualitative Interview Methods with Asian Immigrants. Journal of Transcultural Nursing 20(2): 194-201.

Treas, J., and S. Mazumdar. 2002. Older People in America's Immigrant Families: Dilemmas of Dependence, Integration, and Isolation. Journal of Aging Studies 16(3): 243-58.

Tsang, E.Y., P. Liamputtong, and J. Pierson. 2004. The Views of Older Chinese People in Melbourne about Their Quality of Life. Ageing and Society 24: 51-74.

Veenhoven, R. 2008. Sociological Theories of Subjective Well-Being. In The Science of Subjective Well-Being, ed. M. Eid and R.J. Larsen, 44-61. New York: The Guilford Press.

Vertovec, S. 2004. Cheap Calls: The Social Glue of Migrant Transnationalism. Global Networks 4(2): 219-24

Victor, C., S. Scambler, J. Bond, and A. Bowling. 2000. Being Alone in Later Life: Loneliness, Social Isolation and Living Alone. Reviews in Clinical Gerontology 10(4): 407-17.

Walker, A. 2005. Growing Older: Understanding Quality of Life in Old Age. Berkshire: Open University Press.

Wilding, R. 2006. Virtual' Intimacies? Families Communicating across Transnational Contexts. Global Networks 6(2): 125-42.

Wilkinson, R.G., and M.G. Marmot. 2003. Social Determinants of Health: The Solid Facts, 2nd ed. Denmark: World Health Organization.

World Health Organization. Division of Mental Health and Prevention of Substance Abuse. 1997. WHOQOL: Measuring Quality of Life. Geneva: World Health Organization. http://www.who.int/mental_health/media/68.pdf.

Yin, H. 2015. Chinese-language Cyberspace, Homeland Media and Ethnic Media: A Contested Space forBeing Chinese. New Media \& Society 17(4): 556-72.

Zajac, I.T., I.H. Flight, C. Wilson, D. Turnbull, S. Cole, and G. Young. 2012. Internet Usage and Openness to Internet-delivered Health Information among Australian Adults Aged over 50 Years. The Australasian Medical Journal 5(5): 262-267.

Zhang, J. 2014. Elderly Chinese Migrants, Intergenerational Reciprocity, and Quality of life. New Zealand Sociology 29(2): 11-30.

Zhou, M., and G. Cai. 2002. Chinese Language Media in the United States: Immigration and Assimilation in American Life. Qualitative Sociology 25(3): 419-40.

Zhou, Y.R. 2012. Space, Time, and Self: Rethinking Aging in the Contexts of Immigration and Transnationalism. Journa of Aging Studies 26: 232-42. 